\title{
O ESTUDANTE SURDO, O INTÉRPRETE E O PROFESSOR: UMA DISCUSSÃO BASEADA NAS AÇÕES DESTA TRÍADE NUM CURSO PREPARATÓRIO PARA O ENEM*
}

\author{
Claudia Regina Vieira \\ Andrey Gonçalves Batista
}

\section{Para Início de Conversa}

A Língua Brasileira de Sinais (Libras) foi reconhecida no Brasil no ano 2002 e foi regulamentada em dezembro de 2005 por meio do Decreto Federal № 5626. Para os estudiosos da área essa é uma informação relevante, visto que é preciso considerar os anos anteriores a essa conquista quando falamos em educação de estudantes surdos.

A oficialização era, acima de tudo, uma questão de direitos humanos, na medida em que o uso da Libras era um meio de garantir às pessoas surdas não oralizadas ou que preferissem se comunicar nessa língua a participação na sociedade em igualdade de oportunidades por pessoas ouvintes. Portanto, nesse aspecto, a posição do movimento surdo fundamentava-se essencialmente na configuração discursiva engendrada no seu ponto de partida no contexto sócio-histórico do movimento das pessoas com deficiência. Por sua vez, no campo da educação de surdo, a preocupação fundante das ações do movimento surdo era ainda essencialmente a de assegurar, antes de qualquer coisa, a possibilidade de utilização da Língua de Sinais pelos alunos surdos dentro das escolas e classes especiais, de modo autorizado, protegido pela força da lei (BRITO, 2013, p.131-132)

Antes de 2002, as pessoas surdas vivenciaram anos de abordagens educativas em que a Libras não era considerada como uma língua e uma série de mitos acerca da surdez e dos surdos foram disseminados. A partir da instituição das legislações citadas, uma série de medidas foram tomadas para que a língua de sinais pudesse circular socialmente e para que os surdos

*DOI - 10.29388/978-65-86678-60-4-0-f.129-154 
pudessem ter garantido seu processo de desenvolvimento escolar, a partir de uma educação bilíngue.

É importante salientar que o bilinguismo dos surdos apresenta peculiaridades, pois as duas línguas envolvidas no processo são de modalidade diferentes e a Libras, embora utilizada pela comunidade surda durante há muitos anos teve seu reconhecimento há menos de 20 anos. Não podemos nos esquecer que falamos de mais de 120 anos de proibição de uso desta língua em espaços formais, inclusive nas escolas, pelas comunidades surdas instituído no Congresso de Milão (1880), foram muitos anos de línguas de sinais sendo compreendida sob numa lógica equivocada.

Durante os anos em que a língua de sinais ocupou um espaço de ferramenta de aprendizagem para auxiliar o ensino da população surda e não como responsável pela organização do pensamento, estes estudantes eram vistos como incompletos, nos dizeres de Goffman (1988) fora da categoria socialmente descrita como "normal", pessoas surdas precisavam ser ensinadas a chegar perto dessa tal "normalidade", eram estigmatizadas sem ao menos saber do que eram "capazes". Nestes contextos eram ignoradas a diversidade como característica humana e a reivindicação dos surdos como um povo culturalmente distinto, com uma língua de poder, autores como Strobel (2008), Campelo \& Rezende (2014), ressaltam isso em seus trabalhos e um grupo de doutores pesquisadores surdos lançam um manifesto em formato de carta ao ministro da Educação no ano de 2012 reforçando a importância dessa língua e da educação bilíngue para os surdos.

Portanto, é importante dizer que a partir da legislação, com o reconhecimento da língua de sinais, alguns movimentos para que os surdos pudessem assumir uma posição de maior protagonismo foram realizadas como: a criação da licenciatura em Letras Libras para a formação de professores surdos, de acordo com Lacerda (2009)

Os cursos voltados para a formação do professor de Libras: Letras-Librasportuguês, formarão preferencialmente surdos, podendo também formar ouvintes (conforme prevê a lei). Essas pessoas fariam uma formação Letras/Libras e então estariam aptas a serem professores de surdos no que se refere a sua formação em Libras e talvez (dependendo do foco da formação) português escrito como segunda língua (p.37). 
A legislação atual também instituiu sobre a formação de Tradutores e Intérpretes de Libras e Língua Portuguesa (TILSP) em nível superior, pois de acordo com o artigo 17 do Decreto5626/05 "a formação do tradutor e intérprete de Libras - Língua Portuguesa deve efetivar-se por meio de curso superior de Tradução e Interpretação, com habilitação em Libras - Língua Portuguesa".

Nesse contexto, a Universidade Federal do ABC - UFABC, a partir do ano de 2014 inicia um projeto de Curso Preparatório para o Enem que passa por algumas transformações ao longo dos anos, mas que é o local onde nossa experiência acontece no ano de 2018 e que descreveremos no decorrer deste trabalho. Os dados coletados foram filmados em algumas aulas onde a intervenção entre estudantes surdos e ouvintes - TILSPs - professores ocorreram e serão analisados à luz da teoria histórico-cultural com base em Vygotsky e da linguagem de Bakhtin.

\section{Trajetória da educação de surdos e os processos linguísticos}

Ainda que muitos outros autores já tenham pesquisado sobre a educação de surdos como (BRITO, 1993; GOLDFELD, 1997; LACERDA, 1998; GÓES, 1999; MOURA, 2000; SKLIAR, 1996, 1999; SÁ, 2002), é importante retomar alguns pontos desta história para o tratamento das questões levantadas neste estudo que circunscreve a educação dos surdos três abordagens educativas, são elas: Oralismo, Comunicação Total e Bilinguismo. Oralismo como abordagem educacional prioriza a fala, e todo o trabalho elaborado visa reabilitar os surdos, torná-los "normais", como pontuamos acima, de acordo com os pressupostos de Goffman (2010). Nesta abordagem, é necessário fazê-los falar como se fossem ouvintes, ainda que sem a mesma fluência, entonação e ou entendimento do que se repete, para que a partir daí sejam ensinados. Esse método coloca a responsabilidade do sucesso e/ou fracasso no indivíduo e proíbe o uso dos sinais, por acreditar que estes impossibilitam um esforço para a aquisição da língua oral. Foi imposto a partir do Congresso de Milão em 1880 e vigorou por aqui como alternativa até meados da década 1980.

A abordagem educacional oralista é aquela que visa a capacitar a pessoa surda de utilizar a língua da comunidade ouvinte na modalidade oral como única possibilidade linguística, de modo que seja possível o uso da 
voz e da leitura labial tanto nas relações sociais como em todo processo educacional. A língua na modalidade oral é, portanto, meio e fim dos processos educativo e de integração social (SÁ, 1999, p. 69, grifos nossos).

A Comunicação Total aparece no cenário educacional dos deficientes auditivos como alternativa ao Oralismo. A ideia central da abordagem é permitir o uso de sinais isolados e de todo e qualquer recurso que permita uma comunicação com os estudantes. Isso se configura num grande avanço nos anos 1980, considerando que antes era terminantemente proibida a utilização de sinais/mímicas ou gestos. No entanto, é importante ressaltar que, para a Comunicação Total a tônica ainda é a da reabilitação, portanto, um paradigma médico, e os estudantes ainda são considerados deficientes auditivos em busca de cura.

A educação dos surdos tinha deixado de ser Oralista, na perspectiva teórica, mas as atividades escolares ainda refletiam de forma efetiva o que era proposto no modelo anterior e os professores ainda consideravam que o surdo precisava de reabilitação (VIEIRA, 2017, p. 72).

O bilinguismo, na perspectiva da educação de surdos, ganhou força como possibilidade educacional para estudantes surdos e chega no Brasil no final da década de 1990. Após a promulgação da Lei Federal no 10.436/02 e do Decreto Federal no 5626/05 tenta se consolidar como proposta mais viável, lida com duas línguas de modalidades diferentes: uma espaço-visual, a Libras; e, outra oral-auditiva, a língua portuguesa.

Uma das dificuldades na relação entre as duas línguas e que torna esse tipo de bilinguismo mais peculiar é que a maioria dos surdos não tem acesso à Libras desde a infância, por conta deste pequeno histórico descrito. Um número grande de surdos entra em contato com a língua de sinais somente quando inicia sua trajetória escolar.

Bakhtin e Vygotsky, compartilham o pressuposto de homem como ser histórico e cultural que interage, constrói e (re)constrói, significa e (re)significa com base em sua relação com o outro, neste caso o outro pode ser um outro próximo ou o outro próprio (si). Modifica a si e aos outros, incorpora conceitos e ajuda a transformá-los; nesse mesmo movimento, afirma-se enquanto 
sujeito singular, único mesmo sendo plural, utilizando a linguagem como força motriz nesse processo, capaz de construir conceitos, generalizá-los e utilizá-los da maneira que lhe convém.

Tanto Bakhtin como Vygotsky defendem que a especificidade das funções psíquicas humanas reside no caráter de intermediação; e os intermediários são os instrumentos produzidos e empregados dentro de formas sociais concretas, entre os quais há que se considerar também os instrumentos que se produzem para suprir as necessidades da comunicação social: os signos e, entre eles, sobretudo, a linguagem ${ }^{1}$ verbal (PONZIO, 2015, p. 79).

Nesse contexto, este trabalho se constitui a partir da perspectiva bilíngue para educação de surdos, considerando a Libras e a língua portuguesa fundamentais no processo de ensino-aprendizagem dos estudantes surdos; e, bem como, os pressupostos levantados nos trabalhos de Vygotsky e Bakhtin, no que se refere a língua e linguagem.

\section{EPUFABC como espaço de ensino-aprendizagem e trocas}

A Escola Preparatória da Universidade Federal do ABC - EPUFABC foi criada em 2010, e faz parte de um programa institucional da Universidade Federal do $A B C$ - UFABC que oferece à comunidade externa, exclusivamente para alunos oriundos de escolas públicas, um curso preparatório como uma ferramenta de melhoria nas condições educacionais para a realização do Exame Nacional do Ensino Médio (ENEM) ou outros sistemas de seleção para o Ensino Superior e, por conseguinte, a disputa pelas vagas disponibilizadas no Sistema de Seleção Unificada (SISU), como os cursos da própria UFABC ou vagas de outros programas de seleção como o Programa Universidade para Todos (ProUni).

O impacto educacional de uma formação insuficiente não coloca apenas alunos da rede pública de ensino em maior vulnerabilidade, mas também compromete alunos surdos por conta do histórico já apresentado neste trabalho com o recente reconhecimento da língua espaço-visual que

\footnotetext{
${ }^{1}$ O termo linguagem foi preservado da citação original e não modificado pela autora, por entender que há clareza aqui que o sentido empregado é o de língua.
} 
vem desde então entrar no espaço educacional para promover o desenvolvimento linguístico e cognitivo da população surda.

Conhecendo este cenário nacional da educação de surdos, e principalmente o da região metropolitana de São Paulo, uma professora da disciplina de Libras da universidade propôs a criação de uma Escola Preparatória para o ENEM em Libras que foi chamada de EPLibras. Este projeto tinha os mesmos objetivos que a Escola Preparatória para o ENEM tradicional, a saber:

* oferecer oportunidade para que estudantes pudessem ingressar no ensino superior público;

* que tivessem condições de concorrer a bolsas em instituições de ensino superior privadas.

Essa experiência teve início em 2013 e realizada durante os meses de abril a novembro no período noturno, contou com professores surdos e ouvintes voluntários proficientes que ministravam as aulas em Libras. Ao final do projeto, 17 alunos surdos se inscreveram e prestaram a prova do ENEM, mas nenhum deles conseguiu uma vaga em universidade; no ano de 2014 o projeto foi realizado novamente, no entanto com menos voluntários e com 3 estudantes surdos finalizando o processo, sem conseguirem alcançar uma vaga. Neste mesmo ano a universidade recebia profissionais tradutores intérpretes; e, o ano de 2015 as estratégias foram repensadas, sendo uma delas a de abrir a possibilidade para que candidatos surdos oriundos de instituições privadas pudessem concorrer às vagas, uma vez que recebiam alguma bolsa nestas instituições. Entretanto, não ficando configurado como um privilégio, levando em consideração o histórico de educação para este grupo.

Então, em 2016 teve início a EPUFABC com turmas compostas de estudantes surdos e ouvintes, com a presença de TILSP nas aulas. Esse desenho causou impacto nos estudantes surdos matriculados, visto que experimentaram uma nova forma de participar das aulas, em conjunto com os ouvintes. Nesta organização de turmas, os surdos foram igualmente cobrados, percebendo o quanto estavam "defasados" em relação aos conteúdos e podendo questionar o processo de aprendizagem a que foram expostos. No final do mesmo ano (2016) alguns resultados positivos foram obtidos; por 
exemplo, um dos estudantes conseguiu se matricular no curso de Letras Libras da Universidade Federal de Minas Gerais (UFMG) e uma outra obteve boa nota na redação em um exame de ingresso na universidade.

Além dessa possibilidade dada aos alunos surdos, pode-se observar um impacto positivo nos alunos ouvintes, sem do que muitos se dispuseram a formar duplas, grupos de estudos e de trabalho que incluíam os surdos, promovendo a inclusão educacional de fato. $O$ mesmo ocorreu em relação aos professores, que são estudantes da universidade, que puderam experienciar na prática a diversidade presente nos espaços escolares, seja no aprender a lidar com os estudantes, seja no trabalho em parceria com os TILSP.

Desde então, este tem sido o espaço em que os estudantes surdos encontram oportunidade de estudar para se prepararem para concorrer a uma vaga no ensino superior. E os episódios que serão analisados foram coletados neste espaço.

\section{O espaço da realização das atividades}

No período de 2017 a 2020, as turmas com os estudantes surdos funcionam em um auditório, pois este espaço é composto de uma elevação à frente onde fica a mesa do professor, um quadro-negro grande e um projetor de imagens. No plano oposto ao da elevação, as carteiras são organizadas em fileiras contendo aquelas que são duplas (uma para canhoto e outra para destro); os níveis da sala aumentando gradativamente, de forma que da última fileira pode-se observar a sala na perspectiva mais ao alto. Neste último assento, a visão da lousa, ou mesmo os enunciados escritos apresentados na projeção, podem ficar pequenos desta distância, tendo em vista que a turma se inicia com 120 estudantes e todos os assentos são utilizados. Desta forma, os ocupantes dos últimos lugares dependerão de uma boa visão ou boa audição para acompanharem o curso. 
Figura 1 - Imagem da sala de aula e do Intérprete Atuante

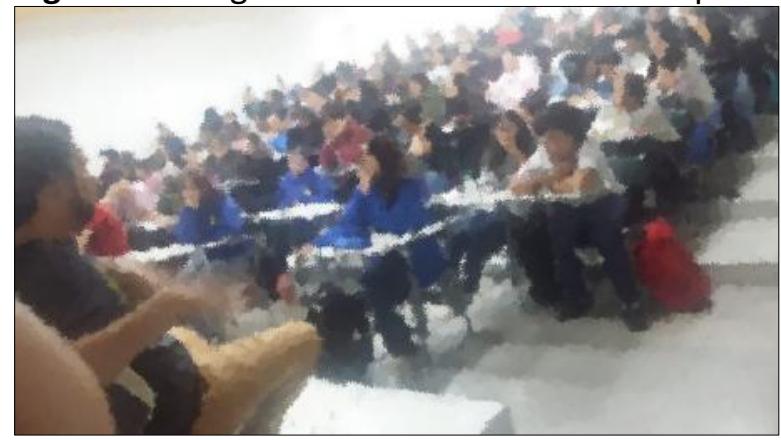

Fonte: Arquivo pessoal dos autores

Na maioria das vezes, os estudantes surdos ficam nas primeiras fileiras e do mesmo lado da dupla de intérpretes de Libras; no entanto, com muita liberdade para circular pela sala em diversas situações, sentam-se próximo a outros colegas de fileiras mais distantes e até já ocuparam os últimos assentos em algumas situações.

A lousa ocupa toda a extensão da parede que fica em frente aos assentos, em um dos lados há uma mesa com um computador de onde as projeções numa tela são controladas. Próximo a este computador, uma cadeira fica a postos para os intérpretes de Libras que se revezam a cada 25 minutos de aula e uma outra cadeira que fica abaixo desta elevação com seu encosto na parede lateral, de forma que a garantir a visão do professor, do quadro, da dupla intérprete e de todos os estudantes.

Figura 2 - Imagem da Visão da Lousa e do Intérprete Atuante com o Professor

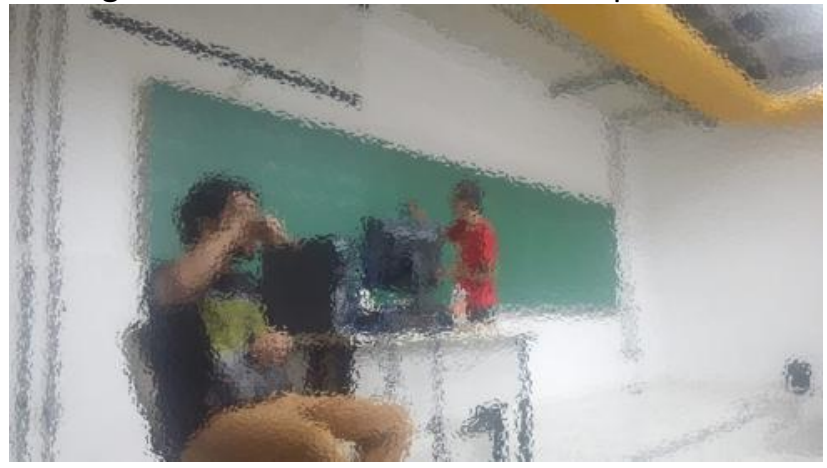

Fonte: Arquivo pessoal dos autores 


\section{A dinâmica: A dupla de intérpretes}

Nas discussões sobre as competências e o papel dos intérpretes na esfera educacional, dos quais destacamos as pesquisas de Albres \& Rodrigues (2018), Albres \& Santiago (2013), Albres (2019, 2017, 2015); Lacerda (2009), Lodi e Lacerda (2009). Para essa reflexão, adotamos a posição de não delimitar os papéis, mas compreendê-los como complementares e colaborativos em todo o processo incluindo os estudantes surdos nesta dinâmica. Essa configuração e pressupõe algumas mudanças na dinâmica da sala de aula e como propõe Lacerda (2009) nos faz repensar o papel do intérprete neste espaço:

A sala de aula tradicionalmente se constitui como um lugar no qual o professor ensina e a criança aprende. Com a entrada do ILS no espaço educacional, acrescenta-se um terceiro elemento que estará lá não só para interpretar da Libras para o português e do português para a Libras, mas também para mediar os processos discursivos entre professor e aluno, almejando a aprendizagem - desse modo, em alguma medida, também o ILS se vê comprometido com a aprendizagem do aluno. Essa nova configuração do espaço escolar certamente demandará ajustes do papel do ILS, do professor e do aluno. Além disso, se trata de uma prática de interpretação com especificidades, já que se dá em um ambiente que propicia uma convivência continua, um certo grau de intimidade tanto com o professor, quanto com os alunos surdos e ouvintes que necessita ser abordada e trabalhada tanto na formação deste profissional, como, posteriormente, em sua prática cotidiana.. (Grifos nossos p. 39)

Como já descrevemos, o projeto foi mudando ao longo dos anos e a atuação dos intérpretes foi se tornando mais fluída, muitas vezes se apropriando do discurso do professor para uma interpretação que trouxesse as caraterísticas dele e não desconsiderasse suas estratégias e metodologias, mas com adequações quando necessário, uma colaboração com o professor das decisões tradutórias. As adequações eram discutidas com os professores em reuniões que poderiam acontecer de acordo com a necessidade no dia-a-dia, seja nas trocas de aulas ou breves conversas no corredor, por e-mail com o envio dos materiais, ou mesmo durante as aulas quando o professor se dirige ao intérprete perguntando como está a compreensão e principalmente: nas 
interrupções durante a fala do professor, como apresentaremos no episódio 1. Isso se dá pela responsabilidade atribuída a função do intérprete com o objetivo de evitar "distorções de informações de conteúdo daquilo que é dito para a língua de sinais, ele deve estar atento às apreensões feitas pelos alunos surdos e aos modos como eles efetivamente participam das aulas". (Lacerda, p.34). Ainda de acordo com Lacerda (2009)

[...] intérprete não traduz apenas o conteúdo de sala de aula, mas também os comentários dos alunos ouvintes e do professor, tomando assim o ambiente escolar acessível ao aluno surdo. Outro aspecto a ser destacado é que, muitas vezes, nas práticas escolares são tratados temas que os alunos ouvintes já conhecem ou já ouviram-falar e que para os alunos surdos constituem ótima novidade, já que não têm acesso as informações orais veiculadas pela mídia, pelos familiares, etc. As crianças e os jovens ouvintes estão a todo momento sendo expostos a comentários e discussões de diversos assuntos abordados pelos adultos e acabam por aprender e obter conhecimentos, estruturando conceitos que irão usar mais tarde em sala de aula. Os alunos surdos, por não terem acesso à comunicação oral, têm menos oportunidade de construir certos conhecimentos, ficando em desvantagem em sala de aula. Cabe ao professor e ao IE sondarem os alunos surdos, entenderem o que eles já sabem ou não sobre diversos temas para que as aulas sejam preparadas levando em conta os conhecimentos construídos e outros que precisam ser forjados (LACERDA, 2009, p.36).

É importante também que os intérpretes adéquem a sua língua de sinais a dos estudantes, de modo que eles possam acessar os conteúdos e também participar das atividades da sala de aula. Como se trata de um curso popular gratuito nem todos os estudantes tiveram acesso aos materiais e conteúdo no Ensino Médio, que são trabalhados na EPUFABC. Muitas vezes, por conta dessas lacunas no processo educacional, os estudantes ficavam com algumas dificuldades, inclusive para se colocarem diante da sala; por isso, essa aproximação entre estudantes e intérpretes é importante e garante aos surdos o espaço e o direito à participação na busca do conhecimento para competir por uma vaga no Ensino Superior.

As aulas da EPUFABC são organizadas da seguinte maneira: 5 aulas de 50 minutos, de segunda às sextas-feiras, com início no mês de março e término após a segunda prova do ENEM; o que geralmente ocorre no mês de 
novembro. Para viabilizar a participação dos estudantes surdos a cada aula, uma dupla de intérprete é escalada, de forma que para cada aula apenas uma troca aconteça. Essas trocas são essenciais para que possa ocorrer um revezamento de funções, a saber:

1. intérprete atuante: este profissional ouve, compreende e diz em língua de sinais o que o professor está dizendo, senta-se ao lado da mesa do professor no piso elevado e fica de frente tendo uma visão da sala toda com os estudantes surdos bem no foco do seu olhar para que possa interagir e captando indícios de compreensão ou não. Quando tem alguma dificuldade, perde alguma informação ou necessita de apoio, olha na direção do intérprete de apoio, que está a postos e solicita a informação.

2. intérprete de apoio: este profissional ouve, compreende a fala do professor e fica a postos para dar suporte ao outro profissional sempre que este solicitar, senta-se numa cadeira fora do piso elevado encostado na parede de forma que tenha de um lado a visão da lousa, do professor e da sua dupla intérprete e do outro os estudantes surdos e também os estudantes ouvintes. Todas as interações dos estudantes surdos com o professor que necessite de interpretação da língua de sinais para a língua portuguesa ficam a cargo deste profissional.

A divisão dessas responsabilidades na atuação permite que o trabalho aconteça, pois, as atenções necessárias para cada uma das situações podem ser realizadas, como quando as falas se intercalam ou no caso de necessidades mais individuais para compreensão. Com esta divisão e este modelo de atuação é possível dar atenção às interações do professor com os estudantes surdos, bem como a dos estudantes surdos para com o professor.

Essa divisão nos mostra que é preciso desmistificar a ideia de que o intérprete de apoio descansa quando assume essa posição; neste momento, a sua atuação tem o objetivo de favorecer que a performance do intérprete atuante não seja interrompida e as interações com o professor possam ser refinadas, buscando diminuir problemas de compreensão.

Cabe a este profissional, que está fora do turno de fala do professor, auxiliar os estudantes que desejam fazer perguntas, considerações e optando por realizar a interpretação de forma simultânea - quando o estudante toma 
a palavra em Libras e concomitantemente enuncia em língua portuguesa -, ou de forma consecutiva - quando o estudante diz em língua de sinais o que deseja, e após o intérprete pede a palavra para traduzir em língua portuguesa o questionamento do estudante.

\section{As aulas, a tríade e os relatos}

De acordo com Pinto (2010), tendo em vista o objetivo de analisar e refletir sobre a atuação dos intérpretes de Libras e as experiências vivenciadas dos estudantes surdos no ambiente do curso preparatório, a análise das atividades buscou a partir dos diálogos e das ações entre os agentes construir categorias que possibilitassem a análise microgenética das situações pedagógicas.

Desta maneira, a atenção esteve voltada não exclusivamente para os pontos gerais das ocorrências, mas da mesma forma para as minúcias e peculiaridades, para aquilo que não está dado, não está evidente. $A$ atenção a detalhes em episódios interativos vincula indícios a condições macrossociais num relato cuidadoso dos acontecimentos, por isso, a análise está frequentemente associada ao uso de videogravação e transcrição (PINTO, 2010, p. 69 - grifos nossos).

A análise microgenética é uma abordagem metodológica que envolve a interpretação histórico-cultural e semiótica dos processos humanos, além de vinculações com aportes teóricos ligados ao paradigma semiótico-indiciário. Uma das linhas diretivas dessa abordagem assume a centralidade da relação entre cultura, história e semiótica no funcionamento humano, quer dizer, parte do pressuposto de que a origem dessa atividade é cultural e social porque se dá na interação com o outro e com a cultura, mediada pela língua.

Por isso, essa forma de análise das interações se faz articulada ao exame do funcionamento dialógico-discursivo, investigando os processos de constituição dos sujeitos por permitir o estudo das relações intersubjetivas.

Com base nesses pressupostos, dividimos a realização de análise em três categorias:

1. Compreensão: A partir das expressões e da interação direta entre intérprete e estudante surdo, a busca pela participação (dúvida, 
afirmação, negação, entre outros processos) para construção e entendimento dos conteúdos expostos.

2. Papel dos intérpretes no processo: A divisão consciente do trabalho que possibilita que cada um possa dentro dos objetivos de atuação intervir no momento adequado.

3. Negociando os conceitos: Intermediar as línguas para que as informações que estão sendo explicitadas se tornem conceitos adquiridos.

Episódio 1 - A interrupção do intérprete colaborando na aula

Aula de Biologia, tema: o corpo humano

\section{Professora:}

[...]então pessoal, agora vamos continuar e começar a falar das Meninges. Elas são um sistema de membranas que vão revestir e proteger o encéfalo e aparecem em três camadas. Vamos estudar as três hoje. A aula está acabando, mas dá tempo. A primeira...

\section{Intérprete (simultaneamente):}

Vamos para um novo tema. M-E-N-I-N-G-E-S. Elas são $\mathrm{M}-\mathrm{E}-\mathrm{M}-\mathrm{B}-\mathrm{R}-\mathrm{A}-\mathrm{N}-\mathrm{A}-\mathrm{S}$ que protegem o cérebro. [estudante fez uma expressão de que não compreendeu]. Há três, uma em baixo da outra.

[interrupção da intérprete] $]^{2}$ : - Professora, como posso traduzir "membrana", o que é membrana?

Professora: É uma pele fininha... bem fina.

Intérprete: - Como assim, pele? Você pode dar um exemplo ou fazer uma comparação?

\footnotetext{
${ }^{2}$ Grifos nossos - para destacar a importância dessa interrupção.
} 
Professora: - Puxa, que difícil. Deixa-me ver se eu sei. Olha, você pode pensar no ovo. Já viu que quando você quebra o ovo, as vezes a gema fica separada? Aquilo que envolve a gema é uma membrana. Quando você põe o dedo, ou quebra com força, a membrana se rompe. Esse é um exemplo muito grosseiro. A membrana não serve apenas para separar, mas também para interagir. Outro exemplo é a célula, ela tem membrana que deixa as coisas passarem ou não por ela para dentro ou fora da célula.

Ficou mais fácil? Deu aí? Só quero ver como você vai traduzir isso. Posso continuar?

Vocês vão ver que elas são diferentes de diversas formas [...]
Intérprete (simultaneamente): Professora está pensando num exemplo para ajudar interpretar. É difícil. Vamos comparar com um ovo. /////////Você quebra e viu, branco e amarelo ficam separados, mas envolta do amarelo tem uma cosia fina envolta de tudo. Aquilo é membrana. Mas é só um exemplo. Há várias membranas de diversos tipos. Membrana só para evitar de que as coisas se misturem? Não. Ela pensou em outro exemplo. A célula tem membrana envolta dela. As coisas entram e sai da célula pela membrana.

Você entendeu? Ficou claro?

[surdo confirma positivamente]

- Pode continuar? Nessa membrana fininha, se você ampliar, vai ver que são três camadas

- que compõe a membrana. São três (uma embaixo da outra).

Fonte: Aula de Biologia da EPUFABC 2019

O episódio nos coloca a discutir aspectos importantes na relação professor-intérprete-estudantes (surdos e ouvintes) dado que no contexto da EPUFABC os surdos ganham o direito a participação efetiva através desta relação e os ouvintes vivenciam como se dá esta interação e muitas vezes são beneficiados com as trocas e com as "interrupções" realizadas durante as aulas, neste episódio descrito a dúvida do intérprete fez com que o professor buscasse um exemplo que tanto estudantes surdos quanto ouvintes pudessem validar o entendimento.

Neste momento, é preciso que o papel dos intérpretes no processo que aparece para nós como uma categoria para análise esteja muito combinado entre as partes (professor - intérprete - estudantes) para que ele possa realizar essa chamada interrupção para assim negociar os conceitos outra categoria para que os estudantes possam acompanhar a explicação.

O entrelaçamento entre estas categorias se dá principalmente porque no exercício da atividade exercida em sala de aula nesta modalidade é imprescindível que o profissional realize a interpretação adequada do fenômeno/conceito explicitado pelo professor, já que se trata de um curso preparatório para o Ensino Superior e também porque a responsabilidade pelo 
conteúdo é do professor, ainda que o intérprete tenha um conhecimento do conteúdo são as palavras do docente que devem ser disseminadas. A interrupção neste caso é uma estratégia para a validação do entendimento e da oportunidade do próprio professor realizar suas intervenções de modo que seu conhecimento do conteúdo seja partilhado entre os estudantes. Por este motivo defendemos que a possibilidade de interrupção deve ser prevista nos espaços educativos.

Todos os diversos campos da atividade humana estão ligados ao uso da linguagem [...] $\mathrm{O}$ emprego da língua efetua-se em forma de enunciados [...] Esses enunciados refletem as condições específicas e as finalidades de cada referido campo não só por seu conteúdo (temático) e pelo estilo de linguagem, ou seja, pela seleção dos recursos lexicais, fraseológicos e gramaticais da língua, mas acima de tudo, por sua construção composicional. (BAKHTIN, 2010, p.261)

No momento do questionamento do intérprete que foi suscitado pelo contato visual na expressão de dúvida do estudante surdo, o próprio professor precisa (re)pensar a melhor forma de oferecer um exemplo, e isso não é só por um processo de "passagem" de uma língua para outra através de vocábulos/sinais, mas uma construção conjunta e colaborativa entre intérprete de Libras e professor.

A língua é o motor que alimenta a mente e faz com que os seres culturais se relacionem e ampliem seus conhecimentos linguísticos e conceituais, para que, dessa forma, continuem aprendendo e transmitindo/recebendo informações, trabalhando-as e incorporando conhecimentos (VIEIRA, 2017, p.92).

O trabalho colaborativo professor - intérprete pode auxiliar nas estratégias didáticas e estabelecer um elo importante que aproxima o docente e estudantes surdos, bem como na quebra de pré-conceitos em relação aos estudantes surdos que desta maneira participam mais em sala.

Episódio 2 - Trabalhando a dúvida da estudante: Significar para enunciar Aula de Biologia, tema: o corpo humano. 
Professora: Neste site vocês vão encontrar todos os animais que estão em risco de extinção. Vejam quantos!
Intérprete (simultaneamente): Veja o quadro. Aqueles animais estão diminuindo em quantidade: Extinção.

[Estudante surda interrompe e pergunta ao intérprete de apoio] Surda: Tenho uma dúvida. Para que precisamos de animais?

${ }^{3}$ Intérprete: Como assim? Quais animais que precisamos?

Surda: Isso, por que precisamos de tantos animais assim. Um monte de animais para que? É. Tipo. Nossa, todo lugar fala que precisamos dos animais. Exemplo, Noé colocar um monte de animais na arca. Por que eu tenho que me preocupar com o boizinho que está lá na África? 0 que isso tem a ver comigo? Não podemos ter só alguns?

Intérprete: Entendi.

Intérprete [interrompe e pergunta a professora]: A estudante está perguntando por que precisamos de uma diversidade tão grande de animais no planeta. E de que forma eles afetam nossa vida?

Professora: Puxa, que pergunta interessante. Vocês entenderam a pergunta dela? Pergunta outra vez, por favor.
Intérprete: A professora pediu para você falar para todos ouvirem sua pergunta. Quer ir na frente?

A estudante posiciona-se a vista de todos e pergunta em língua de sinais com a interpretação em voz da intérprete.

Surda: Porque precisamos de tantos animais, não poderia ser apenas os animais que comemos, usamos a pele e pronto. Eu moro em São Paulo, por que os animais da África são importantes na minha vida? Porque precisamos nos preocupar com a extinção.

Professora: Adorei a sua pergunta e é por causa dela que estudamos e lutamos pelos ecossistemas.

Os seres humanos têm causado sérias modificações que têm impacto não apenas na paisagem, mas em todas as formas de vidas que incluem a nossa. Talvez você não tenha prestado a atenção, mas todas as interações são importantes para a manutenção da vida. Por exemplo, a extinção das abelhas e outros insetos que inviabilizam qualquer plantação. Sem abelha, você não fica apenas sem mel ou flores, mas sem frutas, legumes e muitas outras coisas.

Estamos falando de equilíbrio do
Intérprete: Boa pergunta! É por isso estudamos ecossistema.

Os seres humanos têm prejudicado muito diversos lugares da Terra. Prejudicam todas as vidas, sejam elas grandes ou pequenas. Às vezes não pensamos, mas todas as vidas (grandes ou pequenas) são importantes para todos, humanos, animais, plantas e outros. Exemplo: se acabar as abelhas, o que acontece? Só vai faltar mel? Não. As abelhas vão de uma for a outra, levam o pólen. Se não fizerem isso, não nasce fruta nas árvores. Não tem legumes ou outras comidas.

Cada ser vivo na Terra precisa de equilibrarse com os demais. Tem animais que vivem

\footnotetext{
${ }^{3}$ Neste momento a estudante recorre ao intérprete de apoio, logo o intérprete atuante não pára.
} 
ecossistema. Há animais que viram verdadeiras pragas em determinados ecossistemas quando são introduzidos pelo homem.

Acho que dá tempo. Tem um documentário que mostram que Lobos mudaram o percurso de um rio e todo o ecossistema naquela região.

- Eu vou procurar o vídeo aqui. Enquanto isso, eu quero que vocês me ajudem a definir: o que é ecossistema. Vamos ver se vocês compreendem a dimensão que isso tem na biologia, pois é uma questão da nossa prova da semana que vem. num lugar, mas o ser humano pega e leva para outros, naquele lugar eles prejudicam e destroem, isso se chama: P-R-A-G-A.

Surda: Tem animais que prejudicam?

Intérprete: Sim. Professora vai mostrar um vídeo. Tinha um rio que seguia normalmente, passou um tempo e ele mudou por causa de Lobos.

Surda: Puxa, quero ver!

Intérprete: A professora vai procurar, mas perguntou o que significa Ecossistema. Você sabe explicar em sinais? Tem a ver com a prova.

Fonte: Aula de Biologia da EPUFABC 2018

Este episódio traz um outro entrelaçamento de categorias de análise desta vez compreensão e papel dos intérpretes no processo e isso se dá porque antes de realizar a "interrupção", a estudante surda recorre ao intérprete de apoio, isto porque com a dinâmica estabelecida no interior da EPUFABC, permite que ela possa fazer isso sem que os demais colegas tenham a explicação interrompida.

É interessante que a pergunta dela precisa passar por uma (re)significação. Se fosse interpretada literalmente poderia parecer descabida. Mais uma vez aqui percebemos o quanto é perigoso realizar a correspondência sinal/palavra entre as duas línguas envolvidas neste processo, essa estratégia poderia descaracterizar o questionamento.

A dúvida da estudante neste episódio precisou ser interpretada pelo intérprete, e neste caso a colaboração estudante - profissional foi extremamente importante, no episódio anterior, o intérprete recorre ao professor para conseguir mediar o conceito, neste episódio o intérprete precisa "tratar" a dúvida da estudante, que está se preparando para o ingresso no ensino superior.

À primeira vista, a pergunta "para que servem os animais?" numa aula de biologia sobre ecossistema parece fora de propósito. Poderia evidenciar que depois de várias aulas falando sobre ecossistema e extensão, a estudante não tinha compreendido o óbvio.

No entanto, em vez de censurar a pergunta/dúvida, a intérprete ajudou na elaboração da pergunta. A pergunta "Como assim?" deu espaço 
para que ela conseguisse colocar várias ideias em uma sentença maior e coerente, porque houve tempo e espaço para que elas pudessem estabelecer este diálogo.

Da pergunta inicial interpretada momentaneamente como: "Para que servem os animais?" Obtivemos algo como: “porque precisamos nos preocupar com a extinção e a diversidade da fauna Terrestre?". Quando a estudante surda fez a pergunta inicial, a ideia (para ela) estava completa, pois ela sabia qual era a dúvida, mas não estava ainda elaborada de forma que pudesse enunciar tão adequadamente em Libras.

Essa não é uma exclusividade dos surdos e da Libras, muitas vezes ouvintes pensam em questões que ao pronunciar em voz alta, parece não carregar a intensidade do que realmente querem dizer, sendo necessária uma interação de forma a conseguir elaborar o que realmente se deseja perguntar.

No obstante, aunque los conceptos científicos y cotidianos siguen caminos opuestos en su desarrollo, estos dos procesos se hallan estrechamente interrelacionados. El desarrollo del concepto cotidiano deberá alcanzar un determinado nivel para que el niño pueda asimilar, en general, y tomar conciencia del concepto científico. El niño debe alcanzar en los conceptos espontáneos el umbral en que resulta posible la toma de conciencia. Así, los conceptos históricos del niño inician su camino de desarrollo solo cuando su concepto del pasado está bastante diferenciado, cuando su vida y la de las personas cercanas a él y de quienes le rodean se ha fijado en su conciencia dentro del marco de la generalización primaria de "antes" y "ahora" (VYGOTSKI, 2014, p. 253, grifos nossos).

É importante salientar que na EPUFABC, com o trabalho em duplas é possível garantir que as dúvidas podem ser tratadas, por isso a estudante recorreu ao intérprete de apoio, ficaria muito complicado delegar esta tarefa ao intérprete atuante, que precisaria interromper a interpretação simultânea para cuidar da dúvida, ao passo que com o intérprete de apoio, a dúvida pode ser tratada e o trabalho com o restante dos estudantes só é interrompido quando a dúvida já está lapidada.

O importante aqui é problematizar que não é vergonhoso para o intérprete dar voz a uma dúvida, colocação, argumentação ou opinião do estudante, isso é parte do processo, no entanto, realizar a compreensão da dúvida antes de publicizá-la é uma das tarefas deste profissional, caso o 
intérprete acredite que quem escutará poderá confundir e atribuir ao intérprete essa opinião, o profissional precisa marcar que a fala é do surdo.

Duvidar, errar, se equivocar, confundir e não entender, fazem parte do aprendizado e ocorrem com muita frequência nas salas de aula. Não raro, os professores já pensam que tipo de dúvidas os estudantes podem apresentar quando elaboram o material e ainda assim são surpreendidos com outras formas de raciocínio que aparecem no momento da aula e evidenciam como os estudantes estão organizando logicamente as informações e compondo seu conhecimento.

Episódio 3 - Procurando maneiras de dizer para o outro

História - Egito

Professora: O Egito é politeísta. As divindades egípcias tinham forte impacto na vida dos egípcios. O próprio faraó é um deus na terra.
Intérprete: No Egito, ele tinha um único deus? Não. Tinham vários! Eles eram importantes na vida de cada um dos egípcios. Faraó é deus, vivo que convive com todos na Terra.

Surdo: Aqueles deuses, qual é o chefe?

Intérprete: Como assim, chefe?

Surdo: Qual deles mandam em todos. Tipo, pai dos deuses.

Intérprete: Eu não entendi. Pai de quem?

Surdo: Exemplo, tem ZEUS na Grécia. Ele manda em todos os outros Deuses. Ele é o mais forte. Qual é qual desses deuses do Egito é igual ZEUS? O deus [lobo] e o [arara] eles são os chefes?

Intérprete: acho que entendi.

Intérprete: Professora, uma dúvida do Luciano. A mitologia egípcia tem características similares da grega? Exemplo, existe alguma hierarquia entre eles, como Zeus e os outros deuses. Ele sabe os sinais de alguns deuses que eu não conheço, então vou precisar da sua ajuda: o deus que tem cara de lobo e de arara, como chama?

Professora: Qual? O primeiro é Anúbis e depois tem dois: Hórus e Rá. Qual ele quer saber? Intérprete: [arara] tem 2. Veja.

Surdo: [arara] + cobra.

Intérprete: ele quer saber de Anúbis e Rá. No seu desenho ele o 3ㅇ e o 70 da esquerda para a direita. 
Professora: Anúbis, com cara de lobo ou chacal (risos) é o deus que conduz as almas. Ele leva quem morreu para o submundo. Rá é o deus Sol, mas ele também tem outras formas. Vou ser honesta. Não sou especialista em Egito, grecia e Roma eu domino mais. Preciso fazer uma pesquisa e conheço outro professor que é. Mas ele me deixou com a pulga atrás da orelha. Nunca pensei em fazer essa comparação.
Intérprete: Nome do deus é A-N-U-B-I-S, deus lobo ou C-H-A-C-A-L. Quando a pessoa morre, ele pega a alma e caminha junto até a porta do mundo dos mortos e ajuda a entrar. O outro deus, nome: R-Á. É deus Sol, mas sempre o mesmo rosto? Não. Se você pesquisar vai encontrar vários rostos com nome de rá. Professora disse que não conhece profundamente sobre os deuses do Egito, mas vai pesquisar. Nunca pensou em comparar, sua pergunta a fez pensar.

Fonte: Aula de História da EPUFABC 2019

Mais uma vez, o entrelaçamento entre as categorias compreensão e papel dos intérpretes no processo acontece neste episódio, Luciano procura fazer analogias a partir daquilo que vê "O deus [lobo] e o [arara]", para levar até o intérprete sua dúvida, utilizando o mesmo percurso que a estudante do episódio anterior.

Ainda que ele não conheça os nomes dos deuses em Língua Portuguesa, este desconhecimento não impede que possa colocar sua dúvida. Há aqui o conhecimento do contexto, consegue discutir e argumentar em Libras. Neste caso, tivemos um estudante surdo que gosta de história e tem fascínio pelos temas de Grécia, Roma, Egito e se identifica muito com a professora. Ele tinha conhecimento em língua de sinais e era capaz de discutir sobre mitologia egípcia em língua de sinais, mas não sabia em português escrito o que não invalida seus conhecimentos.

A aprendizagem dos conceitos científicos ou da segunda língua na escola baseiam-se num conjunto de significados da palavra, desenvolvidos previamente e originários das experiências cotidianas da criança. Este conhecimento espontaneamente adquirido medeia a aprendizagem do novo. Assim, os conceitos cotidianos estão "entre o sistema conceitual e o mundo dos objetos" ...exatamente da mesma maneira que a primeira língua de cada um medeia os pensamentos e a segunda língua. Portanto, o desenvolvimento de conceitos científicos depende e se constrói a partir de um conjunto já existente de conceitos cotidiano/s (PANOFSKY; JOHN-STEINER; BLACKWEL, 2002, p.245-246). 
Como estratégia, o intérprete disse que os problemas daquela interpretação se davam pelo desconhecimento dele dos termos em Libras e não o do estudante surdo e ele se valeu de apontamentos e descrições até que obteve os nomes para continuar. No final desta aula, um outro colega ouvinte, mostrou ao surdo um livro de RPG com gravuras de deuses egípcios e o estudante disse que tinha o mesmo livro, vale destacar que neste curso estudantes surdos e ouvintes se relacionam, se entendem como estudantes em igualdade de condições. Embora haja entre dez ou oito surdos na sala de cento e vinte estudantes, as ações desta língua não ficam restritas aos seus falantes e é com todos esses atores que o intérprete de Libras atua. Seja nas relações: professores-surdo ou surdos-professores, surdos e demais estudantes, a interpretação de Libras pode ter forte permeabilidade nos discursos.

Episódio 4 - Por que o alvoroço?

Geografia - Geopolítica

Professora: Um exemplo que podemos considerar é a mutilação feminina. Não se trata apenas de uma questão religiosa, mas também cultural e de desinformação sobre higiene. As vezes acontece quando nasce ou antes da puberdade.

Não acontece só na África não, mas na Ásia, no Oriente Médio e até América Latina.

Professora: Está tudo bem por aí? Estou vendo um alvoroço.

Intérprete: Eu interpretei o termo "mutilação feminina" por "cortar os lábios da vagina e clitóris". E eles não sabiam que isso acontecia, acharam engraçado o sinal de clitóris. 
Professora: Como faz? Me ensina. Olha, até que parece!

Desculpa. Eu não expliquei bem. Na verdade, o termo correto é Mutilação Genital Feminina. Eles cortam, o clitóris, os grandes lábios. Muitas vezes sem anestesia.

(uma aluna ouvinte pergunta: - como assim, cortam as vaginas das meninas?)

Sim, é verdade. Existe a mutilação dos órgãos sexuais, mas há também garotas que amputam os seios para serem confundidas com meninos e não serem estupradas. Esse é um tema pesado. Todos são maiores e podemos marcar um aulão aos sábados para discutir sobre esse tema. O que acham?
Intérprete: Professora está pedindo para aprender o sinal de clitóris.

Ela falou: desculpe. O jeito certo de dizer é MGF - Cortar, genital, mulher. Às vezes sem nada de injeção ou pomada para evitar a dor.

Menina ouvinte lá no fundo de vermelho, falou: "como assim?"

Professora falou que é verdade. Cortam clitóris, lábios da vagina, mas tem outros lugares que as meninas fingem ser meninos, evitam estupro. Sabe como? Cortam os seios! Essa discussão é pesada e deixa as pessoas angustiadas. Se tiver interesse, a professora vai combinar uma aula extra de sábado para falar sobre isso. Vocês querem assistir?

Fonte: Aula de Geografia EPUFABC 2019

Neste último episódio que apresentamos as três categorias se entrelaçam pois, é preciso que haja a compreensão e a negociação de conceitos com a intermediação do papel dos intérpretes no processo. Pela primeira vez o alvoroço ocorre no grupo de surdos, todos acabam de certa forma se manifestando ao perceber do que a professora fala.

Neste episódio é a professora quem dispara o questionamento e a partir dele as dúvidas são apresentadas. A intervenção da professora demonstra a naturalidade com que os estudantes são tratados, pois da mesma forma que ela chamaria a atenção dos ouvintes faz isso com os surdos ao perceber o burburinho. Ela se dirige a eles em vez de interpelar o intérprete. Quando obtém a resposta dada pelo intérprete pede para aprender o sinal que motivou a "interrupção".

$\mathrm{Na}$ interpretação para Libras, quando se falou de mutilação foi necessário dizer o que foi mutilado, o que foi cortado, a espacialidade da língua se manifesta, ao dizer mutilação feminina foi preciso explicitar, não poderia dar o sentido de uma mulher que tem seus braços ou o corpo todo cortado, por exemplo. Como bem lembrado pela professora, o nome é (Mutilação Genital Feminina (MGF), mas por algum motivo, alguns termos têm suas partes suprimidas e aparecem equívocos tanto na sua interpretação para outra língua quanto na própria língua. 
Essa pausa acaba por envolver também os estudantes ouvintes, tanto que uma delas questiona: "como assim, cortam as vaginas das meninas?", a aula passa a ter uma maior participação a partir da interrupção em que a língua de sinais se destaca de certa maneira, a aula acaba sendo inclusive expandida para um "aulão", para possibilitar um maior debate. No caso, o conceito aqui só foi expandido após a discussão sobre o sinal em Libras.

\section{Considerações finais}

Os episódios apresentados nos mostram que o papel dos intérpretes no processo é fator imprescindível para o andamento das atividades escolares na EPUFABC, tanto para os estudantes surdos poderem se colocar, diretamente ou a partir da lapidação de uma dúvida, comentário ou apontamento; quanto para os professores se dirigem aos surdos diretamente e ainda para que os outros estudantes da sala valorizem a participação dos surdos no curso preparatório.

Nas interações durante as aulas, em situações em que há uma boa articulação entre intérpretes - professores - estudantes, constatou-se que é possível trabalhar com novos conceitos e conteúdos, mesmo que eles tenham surgido em um contexto de dúvidas ou questionamentos por um dos elementos dessa tríade.

O trabalho em dupla dos intérpretes - apoio e atuante - com os papéis devidamente determinados, contribuiu com o andamento das atividades, o desenvolvimento dos estudantes e a colaboração com os docentes, visando ao ingresso dos estudantes surdos no ensino superior.

Verificou-se que a EPUFABC, no decorrer dos anos, buscando realizar um trabalho articulado entre os intérpretes e os professores, visando à construção de um espaço realmente bilíngue, oportunizando o acesso aos conteúdos pelos estudantes surdos e evidenciando a importância da língua de sinais neste processo.

\section{Referências}

ALBRES, Neiva de Aquino; RODRIGUES, Carlos Henrique. As funções do intérprete educacional: entre práticas sociais e políticas educacionais. Bakhtiniana, Rev. Estud. Discurso, São Paulo, v. 13, n. 3, p. 15- 
41, dec. 2018. Disponível em: <http://www.scielo.br/scielo.php? script=sci_arttext\&pid=S2176-45732018000300015\&lng=en\&nrm=iso >. Acesso em: 29 jul. 2020. https://doi.org/10.1590/2176-457335335.

ALBRES, Neiva de Aquino. Intérprete Educacional: políticas e práticas em sala de aula inclusiva. São Paulo: Harmonia, 2015.

ALBRES, Neiva de Aquino. Estudos sobre os papéis dos intérpretes educacionais: uma abordagem internacional. Revista Fórum, n. 34, p. 48-62, 2016.

ALBRES, Neiva de Aquino. Afetividade e subjetividade na interpretação educacional. Rio de Janeiro: Ayvu, 2019.

ALBRES, Neiva de Aquino.; LACERDA, C. B. F. Interpretação educacional como campo de pesquisa: estudo bibliométrico de publicações internacionais e suas marcas no campo nacional. Cadernos de Tradução, v. 1, n. 31, p. 179-204, 2013.

ALBRES, Neiva de Aquino.; SANTIAGO, V. A. A. Imagens dos intérpretes de língua de e sinais em sala de aula: escola inclusiva em foco. Revista Sensos, v. 3, n. 2, p. 135-149, 2013.

BAKHTIN, M. Questões de literatura e de estética: a teoria do romance. 6. ed. São Paulo: Hucitec, 2010.

BRASIL. Decreto no 5626. Regulamenta a Lei no 10.436, de 24 de abril de 2002, que dispõe sobre a Língua Brasileira de Sinais - Libras, e o art. 18 da Lei no 10.098, de 19 de dezembro de 2000. Diário Oficial da União, 22 dez. 2005.

BAKHTIN, M. Ministério da Educação. Secretaria de Educação Especial. Lei no 10.436, 24 de abril de 2002. Dispõe sobre a Língua Brasileira de Sinais - Libras e dá outras providências. 
BRITO, F. B. de. O movimento social surdo e a campanha pela oficialização da língua brasileira de sinais. 2013. Tese (Doutorado em Educação) - Faculdade de Educação, Universidade de São Paulo, São Paulo, 2013

BRITO, F. B. de. Integração social e educação de surdos. Rio de Janeiro: Babel, 1993.

CAMPELLO, Ana Regina; REZENDE, Patrícia Luiza Ferreira. Em defesa da escola bilíngue para surdos: a história de lutas do movimento surdo brasileiro. Educ. rev., Curitiba, n. spe-2, p. 71-92, 2014. Disponível em:

http://www.scielo.br/scielo.php?script=sci_arttext\&pid=S01040602014000600006\&lng=en\&nrm=iso>. Acesso em: 29 jul. 2020.

CAMPELLO, Ana Regina; PERLIN, G.; STROBEL, K.; STUMPF, M; REZENDE, P.; MARQUES, R.; MIRANDA, W. Carta Aberta dos doutores Surdos ao Ministro Mercadante. 08 jun. 2012 (mimeo)

GOFFMAN, Erving. Estigma: Notas sobre a Manipulação da Identidade Deteriorada. Rio de Janeiro: Zahar Editores, 1988.

GOLDFELD, M. A criança surda: linguagem, cognição. Uma perspectiva interacionista. São Paulo: Plexus, 1997.

LACERDA, C. Um pouco da história das diferentes abordagens na educação dos surdos. Cad. CEDES [online]. 1998, v.19, n.46, p.68-80.

GÓES, M. C. R. Linguagem, surdez e educação. 2. ed. Campinas: Autores Associados, 1999.

MOURA, M. C. O surdo: caminhos para uma nova identidade. Rio de Janeiro: Revinter, 2000.

PANOFSKY, C. P.; JOHN-STEINER, V.; BLACKWELL, P. J. O desenvolvimento do discurso e dos conceitos científicos. In: MOLL, L. C. Vygotsky e a educação: implicações pedagógicas da psicologia sócio-histórica. 2. reimpressão. Porto Alegre: Artes Médicas, 2002. 
PINTO, G.U. Imaginação e formação de conceitos escolares: examinando processos dialógicos na sala. 2010.Tese (Doutorado em Educação)Universidade Metodista de Piracicaba - UNIMEP, Piracicaba, 2010.

PONZIO, A. A revolução bakhtiniana: o pensamento de Bakhtin e a ideologia contemporânea. 2. ed. São Paulo: Contexto, 2015.

SÁ, N. R. L. Cultura, poder e educação de surdos. Manaus: Universidade Federal do Amazonas, 2002.

SKLIAR, C. (org). A surdez: um olhar sobre as diferenças. Porto Alegre: Mediação, 1996.

SKLIAR, C. (org) Atualidade da educação bilíngue para surdos. v.1 e 2, Porto Alegre: Mediação, 1999.

STROBEL. K. História da Educação de surdos. Apostila produzida para o curso de Letras Libras modalidade a distância. Universidade Federal de Santa Catarina, 2008 (mimeo)

VIEIRA, C. R. Educação bilíngue para surdos: reflexões a partir de uma experiência pedagógica. 2017. Tese (Doutorado em Educação)- Programa de Pós-graduação da Faculdade de Educação da Universidade de São Paulo, São Paulo, 2017.

VYGOSTKY, L.S. Obras escogidas II: pensamiento y lenguaje conferencias sobre psicología. Editorial Pedagógica, Moscú, 1982, De la traducción: José María Bravo, 2001. , De la presente edición: Machado Grupo de Distribución, S.L., 2014. 